\title{
MIRIAM RONZONI Two Concepts Of The Basic Structure, And Their Relevance To Global Justice*
}

\begin{abstract}
G. A. Cohen argues that John Rawls's focus on the basic structure of society as the exclusive subject of social justice is misguided. I argue that two understandings of the notion of basic structure seem to be present in the literature, either in implicit or in explicit terms. (1) According to the first, the basic structure is to be equated with a given set of institutions: if they endorse the right principles of justice, the basic structure of society is just; (2) According to the second, a society has a just basic structure if and only if its institutional web manages to realize the relevant principles of justice as well it can. In (2), the institutional structure is not a given: different social circumstances call for different institutional solutions in order to achieve a just basic structure overall. The first part of the paper make a case for (2), and explores some of its normative implications. The second part asks which consequences this understanding may have for the idea of a global basic structure.
\end{abstract}

KEYWORDS: Rawls, G. A. Cohen, Basic Structure, Social Norms, Global Justice, Cosmopolitanism

\section{Introduction}

In John Rawls' own words, the 'basic structure' of a society is 'the way in which the main political and social institutions of society fit together into one system of social cooperation, and the way they assign rights and duties and regulate the division of advantages that arises from social cooperation over time. ${ }^{11}$ In his view, principles of social justice apply to the basic structure of society and to the basic structure only. Social justice does not require such principles to regulate people's conduct outside the basic structure. As A. J. Julius puts it, ' $[t]$ o conclude that a society is just or unjust, I don't have to know what everyone in the society is doing'. ${ }^{2}$

Rawls' account of what the basic structure is, and of why it should be the exclusive target of attention for theories of social justice, has been the subject of a

\footnotetext{
* I am grateful to Laura Valentini for several inspiring conversations on Rawls and global justice, and to Christian Schemmel for his extensive and extremely helpful comments. I am also indebted to the participants of the Global Justice: Theory, Practice and Rhetoric Workshop at the University of New South Wales (25th26th of March 2006) for helpful feedback. Finally, I wish to thank Tiziana Torresi, Peter Balint, and an anonymous referee for their revising suggestions.

1. J. Rawls, Justice as Fairness, A Restatement (Harvard, Cambridge (MA): Belknap Press, 2001), p. 10.

2. A. J. Julius, 'Basic Structure and the Value of Equality', Philosophy and Public Affairs 31/4 (2003), 321355, p. 321 (emphasis added).
} 
complex debate. ${ }^{3}$ I cannot possibly do justice to the different strands of the debate in this paper. My aim here is only to clear the ground from one misunderstanding about the nature of the basic structure. Such a misunderstanding constitutes, I shall argue, at least part of the ground for the strong intuitive appeal enjoyed by some of the most prominent critiques of Rawls' focus on the basic structure, particularly G. A. Cohen's. Moreover, the misunderstanding has been playing an unappreciated role in debates about global justice - specifically, in the part of the literature which focuses on the existence of a global basic structure as a necessary condition to conclude that the actual global order raises concerns of justice. Hence, while the paper does not have the ambition of justifying the restriction of principles of social justice to the basic structure in a conclusive way, it provides some support in that direction by (1) clarifying how the concept of basic structure should be conceived of, particularly in relation to informal social norms; and (2) arguing that a commitment to the basic structure need not have conservative implications for the global justice debate.

The paper unfolds as follows. In the first section, I present Cohen's critique of the notion of basic structure, highlighting his claim that no intelligible understanding of the basic structure can possibly account for systemic and pervasive injustices that are sustained by informal, rather than legal, coercive mechanisms. In section 3, I put forward an argument against what I believe to be a naïve understanding of the basic structure, and I suggest that the claim that the focus on the basic structure arbitrarily ignores the relevance of informal social norms implicitly relies on such an understanding. I conclude that an alternative understanding should be adopted. In the last section, I ask whether my account has any relevant implications for the debate on the existence and nature of a global basic structure. I argue that it does, although none of these implications can ground a conclusive case for the existence, and the injustice, of a global basic structure. What my argument can deliver are, however, reasons to resist four standard arguments that the current global scenario does not raise any concerns of justice.

\section{Cohen's Critique Of The Focus On Basic Structure}

According to Cohen, the role of the basic structure is overrated: "principles of distributive justice... apply to the choices that people make within the legally coercive structures to which...principles of justice (also) apply'. ${ }^{4}$ In his view, the exclusive focus on legally coercive institutions is morally arbitrary - non-legal patterns of behaviour, like people's selfish individual decisions and discrimination

3. G. A. Cohen, 'Where the Action Is: On the Site of Distributive Justice', in Philosophy and Public Affairs 26/1 (1997), 3-30; D. Estlund, 'Liberalism, Equality, and Fraternity in Cohen's Critique of Rawls', Journal of Political Philosophy 6 (1998), 99-112; A.Williams, 'Incentives, Inequality, and Publicity', Philosophy and Public Affairs 27/3 (1998), 226-24; T. W. Pogge, 'On the Site of Distributive Justice: Reflections on Cohen and Murphy', in Philosophy and Public Affairs 29/2 (2000), 137-169; J. Cohen, 'Taking People as They Are?' in Philosophy and Public Affairs 30/4 (2001), 363-386; A. J. Julius (2003); Iris Marion Young, 'Taking the Basic Structure Seriously', Perspectives on Politics 4 (2006), 91-97.

4. G. A. Cohen (1997), p. 3 (emphasis in original). Cohen additionally specifies: 'In speaking of the choices that people make within coercive structures, I do not include the choice whether or not to comply with the rules of such structures (to which choice, once again, so every one would agree, principles of justice [also] apply), but the choices left open by those rules because neither enjoined nor forbidden by them'. 
within the family, have strong distributive consequences. Hence, justice cannot only be a matter of the state-legislated and coercive structure in which people act (law, taxation, etc.), but is also a matter of what people choose to do within that structure. Nor, so Cohen argues, can Rawls overcome the problem by arguing that although the primary subject of justice is the basic structure of society, the basic structure includes more than the legally coercive structure of a social system. ${ }^{5}$ Rawls indeed claims that the basic structure consists of the major social institutions of a society, and this says nothing as to whether we should have an exclusive focus on coercive institutions. However, Cohen contends, once this line is crossed, no intelligible notion of basic structure is available any longer. When it comes to non-coercive structures, he argues, the distinction between the choices which constitute the structure, and the choices that occur within it, cannot be made as clearly as in the case of coercive structures. The rules that define the very nature of such structures depend on the choices that people routinely make within them: 'When A chooses to conform to the prevailing usages, the pressure on B to do so is reinforced, and no such pressure exists, the very usages themselves do not exist, in the absence of conformity to them'. ${ }^{6}$ This, however, means giving up on the notion of basic structure altogether, since the focus on the basic structure is meant to free citizens from the burden of considering the consequences that their daily choices may have by giving them 'the knowledge that elsewhere in the social system the necessary corrections to preserve background justice are being made'. ${ }^{7}$ The only way out for Rawls would be, then, to stick to a strictly coercive understanding of the basic structure. This, however, would be morally arbitrary in the light of Cohen's first critique: if the rationale for the focus on the basic structure is the depth and pervasiveness of its effects, then many non-coercive patterns of behaviour cannot be excluded from the realm of social justice.

Before I move on to offering a response to Cohen's critique, a caveat needs to be made. Rawls and Cohen do not disagree on whether the basic structure is the only thing that is capable of being just or unjust, and Rawls is not committed to such a view. In his account, many things can be called just or unjust (laws, attitudes, persons, etc. $)^{8}$, however, different criteria and considerations apply when we assess their justice. The justice of society, in Rawls's account, is determined by the justice of its basic structure ${ }^{9}$, and the principles that apply to the basic structure are different from the principles that apply, say, to individual conduct. The argument I intend to develop in this paper has nothing to say about the debate over whether institutions, and institutions only, can be just or unjust, since this is not the debate in which Cohen and Rawlsians are engaged. The issue at stake between Cohen and Rawlsians concerns two narrower points, that is:

a) Is social justice (as opposed to other forms of justice) only determined by the

5. Ibid., pp. 17-24.

6. Ibid., (emphasis added).

7. See J. Rawls, 'The Basic Structure as Subject', in Political Liberalism (New York: Columbia University Press, 1993), 265-271, p. 269.

8. J. Rawls, A Theory of Justice, Revised Edition (Oxford: OUP, 1999), p. 6. 9. Ibid. 
basic structure of society?

b) Do principles of justice for the basic structure differ from principles of justice for individuals, private associations, etc.?

As I stated above, I am not going to provide conclusive, positive answers to (a) and (b). My aim is more modest: I intend to elucidate what it means for a basic structure to be just, since I believe that many - though by no means all - perplexities about Rawls's focus on the basic structure stem from a flawed understanding of what a society with a just basic structure would look like in the first place.

\section{The Notion Of 'Legally Coercive Structure': A Common Misunderstanding}

Imagine that society $\mathrm{S}$ is committed to equality of opportunity between men and women, in that it prohibits official, explicit discrimination. Society S's educational system also tries to promote fair (rather than purely formal) equality of opportunity through, among other things, an educational system that genuinely guarantees equal opportunities for access to selective schools for females and males. This is a quite standard interpretation of fair equality of opportunity. However, the pattern of rules within the family in society $\mathrm{S}$ generates strong pressure for females not to apply for selective schools in the first place.

Cohen would arguably claim that society $S$ is unjust, in spite of the impeccability of its basic structure. I regard his overall normative assessment of society S as right, but for the wrong reasons. I shall suggest that society $\mathrm{S}$ is unjust because it has an unjust basic structure, and that it is possible to make such a claim while maintaining an intelligible notion of basic structure.

In order to make sense of this claim, I shall concentrate on the theoretical structure of Rawls' theory of justice, which can approximately be laid out as follows:

1. The appropriate principles of social justice are those which would be chosen in the original position and reasonably satisfy reflective equilibrium.

2. The subject of social justice is the basic structure of society.

3. The basic structure of society should be regulated by the principles of justice delivered by the theory according to (1).

4. When (3) is satisfied, the basic structure of society is just, and hence the society itself is just.

I shall argue that, even if we endorse a purely coercive and institutional understanding of the basic structure, there is still a large ambiguity as to how (3) should be interpreted, and it is an ambiguity that plays a major role in determining whether (4) holds or not. The ambiguity is due to the fact that two possible interpretations of (3) are available. I shall call such two interpretations $\mathrm{X}$ and $\mathrm{Y}$, and lay out how they would respectively conceive of and articulate (3).

In both $\mathrm{X}$ and $\mathrm{Y},(3)$ would be articulated into two different claims. In X, such claims are:

$3 \mathrm{i}(\mathrm{X})$. First, we determine what the basic structure is and which institutions are part of it; 
3ii(X). Then, we should design these institutions (and these institutions only) in a way that respects Rawls's two principles of justice.

In Y, condition (3) is interpreted in the following, significantly different way:

3i(Y). First, we should understand which conditions have to be in place for us to be able to say that in a given society $\mathrm{S}$ such principles are satisfied;

3ii(Y). Then, we have to ask which institutional structure needs to be set up in order to allow the principles of justice to be realised in the sense specified by $3 \mathrm{i}(\mathrm{Y})$, in the specific context in which we are operating.

In both models, social norms and informal mechanisms of pressure are not, technically speaking, part of the basic structure. But in Y, unlike in X, their nature and effects are essential to determine whether the basic structure is just, and hence, the fact that they are not directly part of the basic structure becomes, in a way, much less of a fundamental issue. If we think that the context determines at least partly which institutional structure is to be considered just, then informal rules and norms do play a significant role in the assessment of our basic structure, even if we do not conceive of them as direct part of the basic structure.

The main idea in model $\mathrm{X}$ is that the structure of an institutional framework is something fixed and given, that cannot be questioned. Model $\mathrm{X}$ is therefore committed to concluding that the basic structure of society $\mathrm{S}$ is just, although ineffective due to injustices that take place outside it. The question whether, in order to realise the principles of justice properly in the light of the specific features of society $\mathrm{S}$, we need to regulate more phenomena, or in a different way, does not arise. Given this account of what the basic structure is, it perfectly makes sense to claim, as Cohen does, that a society can be unjust even if its basic structure is just. However, I believe that what does not make sense is precisely to conceive of the basic structure in this way, for two reasons that I expose in turn.

Firstly, asking whether an institutional setting respects certain principles of justice without scrutinising its structure, scope and strategy in the light of the context which it is going to organise is not an intelligible enterprise. Institutions are created to realize certain standards of justice, and whether they succeed in doing so is the criterion according to which we should assess their justice. But whether institutions fail or succeed in realizing a standard of justice largely depends on the context in which they operate, and the specific obstacles that they are expected to encounter. If a society affirms fair equality of opportunity, but fails to address the main existing obstacles to fair equality of opportunity through its institutional setting, our legitimate concern is that such a society might not have the right institutions. Let us assume, for instance, that in society $\mathrm{T}$ the main obstacle to equality of opportunity between men and women is a social rule, which considers socially unacceptable that women engage in public life. Society $\mathrm{T}$ is committed to Rawls' principle of fair equality of opportunity, and accordingly sets up two institutional mechanisms to promote it: 1) a constitutional protection of fair equality of opportunity, and 2) an educational system which gives women privileged chances to be trained and become qualified for positions of advantage in public life. In society $\mathrm{T}$, however, women are already expected to be well 
educated. The social expectation for the good wife and mother is to be capable of being an entertaining and brilliant host, of organising and running intellectually stimulating dinner parties, and, most importantly, of adequately attending to the education of her children. Hence, the problem with the institutions of society $\mathrm{T}$ is not that they violate or deny fair equality of opportunity, but rather that they fail to do what needs to be done in their specific context - they miss the target. Women of society $\mathrm{T}$ do not need a better education, but rather a set of institutional devices to protect those of them who decide to go against what is socially expected of them, by making their choices more realistic, less costly, and less stigmatising. Model Y can accommodate this, but model X cannot. Model X does not allow for any space to decide what the basic structure should be like in the light of contextual consideration, rather than in abstracto. This, however, makes the enterprise of scrutinising the normative credentials of an institutional setting virtually unintelligible.

Secondly, model $\mathrm{X}$ ridiculously narrows the possibility to compare different institutional structures in terms of justice. Let us focus, for instance, on freedom of the person, understood in terms of 'freedom from psychological oppression and physical assault and dismemberment'. ${ }^{10}$ In society T criminal law is designed in such a way to criminalise most actions which violate it, and both the police and the judiciary are reasonably effective in fulfilling their duties when violations of freedom of the person occur. However, not many institutional mechanisms are in place to remove the main social factors that cause most of such violations to occur in the first place. Several elements 'outside the basic structure' of society T cause violations of freedom of the person to occur: urban segregation, problematic racial integration, social acceptance of domestic violence, etc. Society $Z$ has more or less the same social and cultural features of society $\mathrm{T}$. It also has all the institutional mechanisms to protect freedom of the person that the basic structure of society $\mathrm{T}$ has in place. The difference between society $\mathrm{T}$ and society $\mathrm{Z}$ is, however, that society Z has put several more institutional mechanisms in place, and mechanisms of a different kind: community centres in deprived areas, state-funded nightlines for cases of domestic violence, etc. These additional institutional mechanisms have no negative spillovers on other basic liberties. ${ }^{11}$

Model X assesses the justice of institutions in a vacuum, without evaluating them in the light of a given context, it therefore evaluates whether institutions are just or not per se. Hence, a claim that the basic structure of $\mathrm{Z}$ is more just than that of $\mathrm{T}$ would commit the advocate of $\mathrm{X}$ to the conclusion that any society which does not have community centres for deprived areas, nightlines for cases of domestic violence, etc. falls short of having a just basic structure. This however, would be blatantly false of a society with no significant problems of segregation and domestic violence, but had other threats to freedom of the person that are appropriately addressed with a different set of institutional devices. However,

10. Rawls (1999a), p. 53 .

11. This caveat is justified by the fact Rawls' first principle of justice prescribes an equal total system of basic liberties. Hence, if the additional institutional mechanisms of society $\mathrm{Z}$ had negative spillovers for other basic liberties, a Rawlsian could have reasons to prefer the institutional setting of society $\mathrm{S}$ all things considered. 
claiming that society $\mathrm{Z}$ is more just than society $\mathrm{T}$ does not entail that the basic structure of every society would need to implement the same institutional mechanisms as $\mathrm{Z}$ in order to satisfy the relevant standard of justice. The basic structure of $Z$ is simply more just because it reacts better to its specific context. Society Z's state-funded nightlines for rapes and domestic violence on women might, taken on its own, violate equality between men and women (by devoting extra resources to women), but they might make the overall system of society $Z$ more just. Such a distinction can, however, only be drawn in model Y, where an institutional structure is considered just if it succeeds in realizing the appropriate standard of justice in the specific context in which it operates.

Thomas Pogge suggests a similar point through his claim that Rawls's model of 'justice as fairness' is a three-tiered account of justice. ${ }^{12}$ The parties in the original position (tier 1), select a criterion of justice (tier 2, the two principles of justice), which are meant to be guidelines for the design of the basic structure for any specific empirical context (tier 3). Two-tiered theories, on the other hand, elaborate a selection procedure (tier 1) in order to spell out principles of conduct (tier 2) that the relevant set of agents ought to follow. Rawls' two principles of justice are a criterion of justice that is meant to offer guidance to design, reform, and adjust an institutional structure, rather than, say, direct principles of conduct for institutions, whatever this might mean. ${ }^{13}$ Hence, there is no direct, automatic way in which a criterion of justice can be translated into an institutional order: this is highly sensitive to specific contexts and empirical circumstances. ${ }^{14}$ There are, so to speak, no clearly identifiable 'principles of conduct' that institutions can safely follow, thus securing their pedigree in terms of justice. In this perspective, model X seems to endorse a two-tiered conception of justice: the principles of justice are, in some sense, conceived of as direct 'principles of conduct' that the institutions of a society must 'follow'. My argument against model X can then perhaps also be phrased as an objection against the plausibility of two-tiered theories of justice for institutions: in X, principles of justice are regarded as principles of conduct that are directly applied to institutions and thus make the basic structure just, whatever the context of the relevant society might be. My argument so far, however, has shown the absurdity of conceiving of principles of justice for institutions as principles of conduct: institutions are created and designed by us, they are artificial entities that we bring about in order to realize a desired normative standard, and that is the criterion according to which they ought to be assessed.

My main point should by now be clear: in Y, no basic structure is just if it fails adequately to respond to the context it is meant to be applied to; in $\mathrm{X}$, this is not the case. If we endorse model $\mathrm{Y}$, even within a legal understanding of the basic structure, an attention to the wider context, to social rules and non-coercive

12. T. W. Pogge, 'The Incoherence between Rawls' Theories of Justice', Fordham Law Review 72/5 (2004), 1739-1759.

13. Pogge clarifies this difference by showing how Rawls' principles of international justice - as they are laid out in The Law of Peoples - are, instead, principles of conduct, which tell agents (in the specific case, peoples) directly what to do.

14. See also Rawls' four-stage sequence; Rawls (1999a), pp. 171-176. 
structures is everything but ruled out. Complementarily, even if some aspects are external to the legal basic structure, the basic structure can have an impact on them, and such an impact plays an essential influence on our assessment. ${ }^{15}$ This allows us to reassess Cohen's claim that no intelligible notion of basic structure can include informal social rules, because such rules are what they are precisely in virtue of people's behaviour. If the argument spelled out so far is sound, informal social rules are sustained, not only by people's chosen behaviour, but also by a basic structure which allows them, encourages them, and partly shapes them. In the interpretation of basic structure that I have put forward, social rules do not come into existence in a vacuum, but against the background of a general structure of incentives and rewards. Hence, if we endorse model Y, having a legally coercive understanding of the basic structure does not arbitrarily exclude unjust social norms, because (1) social norms are not conceived of as fully independent from the general background created by the basic structure, and (2) the normative assessment on the basic structure is not itself independent from the context - including social norms and informal pressure - in which the basic structure is meant to operate. ${ }^{16}$ As Joshua Cohen claims, the basic structure does not 'take people as they are'17, and, conversely, there is no fixed and given way in which people 'are' in a vacuum, independently from the institutional shape of society. Going back to our initial example, if in society T social norms pressurize women into not applying for competitive schools, a schools system which offers equal access to women and men, while failing to create extra incentives and opportunities for women, may fall short of being just. In order to achieve equality of opportunity, the basic structure of society $\mathrm{T}$ needs to be responsive to the sexist social patterns within the society, which it is not.

Let me conclude this section by stating that my argument is not a comprehensive response to Cohen's critique of the basic structure. Cohen has other reasons for rejecting an exclusive focus on the basic structure, which I have not addressed in this paper. Finally, I have not argued that the endorsement of model Y would eliminate the difference between Cohen's and Rawls's approach. My argument is simply that a focus on the basic structure need not be blind to social norms and informal mechanisms of pressure. Cohen never commits to an understanding of the basic structure similar to model X. However, once we start conceiving of the basic structure in the way I have suggested we should do, some of his examples loose their bite. Consider, for instance, the following claim:

Expectations...in the family are sexist and unjust if, for example, they direct the woman in a family where both spouses work outside the home to carry a greater burden of domestic tasks. Yet such expectations need not be supported by the law for them to possess informal coercive force: sexist family structure is consistent with sex neutral family law. ${ }^{18}$

15. This does not entail, however, that we can shape our basic structure in an all-pervasive way. Even in interpretation $\mathrm{Y}$, then, there are limits to the demandingness that the institutional structure may legitimately have. I discuss this problem in a different paper: Miriam Ronzoni, 'The Limits of the Basic Structure, or the Separation between the Right and the Good' (unpublished manuscript).

16. See also Pogge (2000).

17. J. Cohen (2001).

18. G. A. Cohen (1997), p. 22, emphasis added. 
The intuitive force of this example is precisely that it implicitly relies on an understanding of the basic structure which is strikingly similar to the one implied by X. Such an example does not constitute a problem whatsoever for model Y: in a sexist society, sex neutral family law may well be an unjust institution. ${ }^{19}$

\section{The Global Basic Structure: Does It Exist? Is It Unjust?}

The argument spelled out so far has lead us to the conclusion that, even if we endorse a legally coercive understanding of the basic structure - and hence do not consider social rules as being directly part of the basic structure - we are nevertheless bound to consider social rules and informal mechanisms of pressure as essential in order to determine whether our basic structure is just. The last claim has to be interpreted in a bi-directional way: a basic structure is just (1) if it adequately responds to the problematic norms and habits of a specific social context; and, conversely, (2) if it does not engender a structure of incentives and rewards that will tend to produce what Cohen calls 'unjust' social rules. No basic structure is just or unjust in abstracto - with some obvious exceptions for institutional settings that would violate the two principles of justice in all possible empirical circumstances. This has important implications for many fields: the role of the family, the nature of the 'private' sphere, and how institutions can support victims of social pressure, provide some examples. In what follows, I focus on one such implication (arguably the least obvious one): the idea of a global basic structure.

In Political Theory and International Relations ${ }^{20}$, Charles Beitz advances the claim that, in our world, a consistent Rawlsian must be committed to advocate that principles of justice apply globally, given the indisputable presence of a global basic structure. The level of global economic interdependence, Beitz argues, '[i]nvolves a pattern of transactions that produce substantial benefits and costs'. ${ }^{21}$ Moreover, the world economy has evolved its own financial and monetary institutions, and 'taken together, these institutions and practices can be considered as the constitutional structure of the world economy; their activities have important distributive implications'. ${ }^{22}$ Hence, a global application of Rawls' theory of justice seems to be required. Ten years later, Pogge puts forward a similar, although not

19. One last question may arise at this point: if a basic structure, in order to be just, has to be responsive to the problematic social norms of the social system it is meant to regulate, do we not need an account of counts as an unjust social norm? And if this is the case, are we not back at the initial point, namely that of establishing whether the same principles of justice apply within and outside the basic structure? Not necessarily. The point I have been defending is the following: saying that a principle of justice applies to an institutional system does not mean that the institutional structure should act on that principle, but rather that it should realize it. For instance, fair equality of opportunity, as a principle of justice for institutions, does not (only) demand that, say, institutions themselves do not discriminate between men and women, rich and poor, etc., it mainly demands that institutions be organized in such a way that the reasonable expectations of equally talented people coming from different sexes, background and races be roughly equal. What that requires, in terms of institutional actions, depends on the context, including the set of prevailing social norms. This, however, is very different from claiming that the social norms themselves should endorse fair equality of opportunity, the difference principle, and the like.

20. C. R. Beitz, Political Theory and International Relations (Princeton: Princeton University Press, 1979), pp. $143-153$.

21. Ibid., p. 148.

22. Ibid., pp. 148-9. 
identical, position in his Realizing Rawls. ${ }^{23}$ Responding to both in The Law of Peoples $^{24}$, Rawls rejects the idea of a permanent global redistributive measure. International redistribution, Rawls argues, can be justified in terms of fulfilment of a 'duty of assistance' towards 'burdened societies', i.e. societies which 'lack the political and cultural traditions, the human capital and know-how, and, often, the material and technological resources needed to be well-ordered'. ${ }^{25}$ Such a redistribution, however, would not be continuous, but it would rather have 'a target $^{\text {'26 }}$, namely to put burdened societies back on their feet. On the contrary, an on-going international distributive scheme would be disrespectful of the diversity of choices that lead different societies to have different levels of wealth: if society A and society B make different decisions in terms of, say, industrialisation or birth control, and such decisions have a radical impact on their affluence, a constant transfer of resources would fail to take these decisions, and their consequences, seriously enough. ${ }^{27}$ Hence, by concentrating on the necessity to respect the choices of different societies, Rawls seems to suggest that such choices are to be considered as relatively autonomous and self-contained, and consequently that nothing like a full-blown basic structure - which distributes 'fundamental rights and duties and determine the division of advantages from social cooperation,28 - can be said to exist at the global level. If an on-going international distributive scheme would be, as Rawls seems to hint, unfair towards the ant and too generous with the grasshopper, then the grasshopper and the ant are conceived of, at least to a very high extent, as relatively independent and unrelated to each other's fate. More recently, David Miller has restated this point more explicitly, rejecting the idea that the level of current global interaction and interdependence is sufficient to ground the case for the existence of a global basic structure in the proper sense. ${ }^{29}$

The endorsement of a legally coercive understanding of the basic structure seems to lead towards the side of the anti-global basic structure camp. If the basic structure is to be understood as a web of formal, legally coercive institutions, then the arguments raised by the advocates of a global basic structure seem to lose most of their bite. The aspects of the global order they tend to look at are phenomena like the following:

- 'Unwritten rules' that strongly influence the distribution of resources and wealth across different societies (e.g. what can and cannot be done to superpowers).

- International institutions whose membership is officially optional but which, de facto, make the 'rules for everybody' (most notably, the World Trade Organization).

23. T. W. Pogge, Realizing Rawls (Ithaca: Cornell University Press, 1989), pp. 211-280.

24. J. Rawls, The Law of Peoples (Cambridge (MA): Harvard University Press, 1999), pp. 115-20.

25. Ibid., p. 106.

26. Ibid., p. 117.

27. Ibid., pp. 117-8.

28. Rawls (1999a), p. 6.

29. D. Miller, Principles of Social Justice (London, Cambridge (MA): Harvard University Press, 1999), pp. 245268; D. Miller, 'Justice and Global Inequality, in A. Hurrell and N. Woods (eds.), Inequality, Globalization, and World Politics, (Oxford: OUP, 1999), 187-210; D. Miller, Citizenship and National Identity (Cambridge: Polity Press, 2000), pp. 161-79. 
- Differential treatment in terms of free-market policies ('rich countries are particularly protectionist in many of the sectors where developing countries are best able to compete ${ }^{30}$ ).

- Deep inequalities in expertise, and hence power and bargaining power, between affluent and poor countries ('Our representatives ruthlessly exploit their vastly superior bargaining power and expertise, as well as any weakness, ignorance, or corruptibility they may find in their counterpart negotiators, to shape each agreement for our greatest benefit ${ }^{31}$ ).

- A system of international relations which discourages, rather than incentivises, the flourishing of democracy and of the rule of law in developing countries (e.g. what Pogge calls the 'borrowing privileges of authoritarian predators ${ }^{32}$ ).

This category of phenomena could be approximately compared, at least for the present purposes, to what we have been calling 'informal social rules' in the domestic scenario: they are systemic and patterned in nature and have deep and pervasive effects, but they are not, in the strict sense, formal and legally coercive rules. If this is the case, the position outlined in this paper seems to be committed to concluding that there is no global basic structure. If, in Rawlsian terms, we think that the basic structure is the appropriate and exclusive locus of justice, my account seems to lead to the conclusion that no concerns of justice arise at the global level, since no proper global basic structure can be said to exist. Cohen, on the contrary, encounters no such problem: the presence of deep inequalities caused by 'unjust chosen behaviour' of global actors in the international arena would be perfectly enough for him to claim that there is a case for global (in)justice.

I am not convinced that such a rigid conclusion follows from my position. If my understanding of the basic structure alone cannot deliver a conclusive answer in the global justice debate, it can nevertheless provide good reasons to reject some easy ways of dismissing the problem of global justice. The argumentative strategy of the remainder of the paper is, therefore, negative in nature. I will present four arguments that are usually advanced to reject the idea that we should think of the global order in terms of 'justice'. All four arguments are related to the notion of basic structure: the first two express the idea that there is no global basic structure, and hence no locus of global justice; the third claims that there might be such a thing as a global basic structure, but that it is not unjust; the fourth suggests that, even if there was such a thing as a global basic structure, domestic factors surely would also play a role, and thus a heavy global distributive scheme - like a global 'difference principle' - would still be excessively demanding, and ultimately unfair. I am going to present these arguments in an 'anonymous' version, i.e. I am not going to attribute them to anybody in particular. My reasons for doing so are twofold. Firstly, I believe such arguments to underlie, rather than explicitly sustain, much of the literature against global (distributive) justice. Secondly, my interest in these arguments is justified not only by the role I detect them playing

30. The Economist, September 25, 1999, p. 89, quoted in T. W. Pogge, World Poverty and Human Rights: Cosmopolitan Responsibilities and Reforms (Cambridge: Polity Press, 2002), p. 17.

31. Ibid.

32. Pogge (2002), pp. 22-3, 113-15. 
in the literature, but also by their presence in common morality - particularly in the widely shared view that poverty and misery abroad is highly deplorable, but is not a concern of justice that should consequently 'really' unsettle us.

\section{1. 'There is noglobal legally coercive structure that genuinely involves all global actors and is equipped with formal and legal mechanisms of enforcement. Hence, there is no problem of global justice.'}

This is probably the most standard line of argument: there is no global 'state', and hence, in an institutional understanding of justice, no real agent to whom we can legitimately attribute the predicates 'just' or 'unjust'. The examples provided by cosmopolitans to suggest that we actually have a global basic structure, so the argument goes, are not compelling. Some of these examples are simply effects of the 'chosen behaviour' of, and agreements between, global actors, that is, something that we would not regard as part of the basic structure at the domestic level. Others are cases of non-legal rules and informal pressure, and as Cohen has convincingly argued, such kinds of norms and patterns of behaviour cannot be part of the basic structure if we are to maintain an intelligible understanding of this notion. Other phenomena that cosmopolitans point at are, indeed, institutions; but they are not institutions in the relevant, legally coercive sense. International institutions are most of the time 'optional', that is, no global actor or state is forced to participate; states can more or less freely decide whether it is in their long-term interest to do so. Surely, most of the time, it happens to be the case that participation is so clearly a better prospect than non-participation that the choice to opt out is not even taken seriously; nevertheless, this scenario is still significantly different from the domestic basic structure, which is, as Rawls claims, 'present from the start' 33 , and is not something we can opt out from in any intelligible sense. Thus, international institutions are rather to be compared to what Rawls calls voluntary associations of civil society in the domestic case, and, as Rawls himself contends, principles of justice for the basic structure do not apply to them. ${ }^{34}$ Moreover, in many cases, even when global institutions are meant to be non-optional (like international law), or at least to have some legal power over their participants (like the United Nations), they lack an overarching structure which can actually grant them the capacity to enforce rules and impose regular and foreseeable sanctions over non-compliers. Most of the time, enforcement and sanctions are themselves optional, irregular, strongly influenced by considerations of ad hoc appropriateness, political wisdom, effectiveness etc.

It seems that, if one endorses a legally coercive understanding of the basic structure, one is also bound to accept this conclusion. Consider, however, the specific understanding of legally coercive basic structure that I have been spelling out in this paper: one of its main features is that, although non-legal norms and patterns are not directly part of the basic structure, they are essential to determine whether the basic structure is just. What matters is 'the actual system' 35 that is to

33. Rawls (1999a), p. 7.

34. 'The principles of political justice are to apply directly to this structure [the basic structure of society], but are not to apply directly to the internal life of the many associations within it'; J. Rawls, 'The Idea of Public Reason Revisited' in Rawls (1999b), p. 158.

35. Pogge (2000), p. 165 (emphasis in the original). 
be organised, and the nature of that system largely determines which design of the basic structure actually satisfies the requirements of justice, and, specifically, what and how much should be regulated by the basic structure. A careful scrutiny of informal rules, mechanisms of pressure and distributions of power does not tell us what is part of the basic structure, but it does tell us what ought to become part of it. The concept of basic structure, in a way, is there to invite us to decide what the appropriate boundaries of the political are. If leaving certain areas of interaction unregulated will heavily distort the 'division of advantages that arises from social cooperation over time', there is a case for saying that some phenomena are not, but ought to be, regulated or at least shaped and informed by the influence of the basic structure.

Consider, for instance, the case of international agreements and 'chosen behaviour' between global actors. If such agreements are heavily distorted by differentials in power and expertise, and they lead to unacceptable results and exploitative implications, there is a case to say that something like a 'basic structure' intervention is needed. To make more vivid sense of this point, compare the case of international agreements in an unequal world with the case of industrial labour in a pre-trade unions and pre-labour law era. In such a scenario, 'agreements' between employers and the labour force could culminate in all possible forms of labour contracts, including contracts involving precarious employment, child labour, long working hours, dangerous working conditions, and bad pay. In a world where labour contracts are not regulated in any way, we must indeed concede that, under a strictly legal understanding of the basic structure, labour relationships fall outside the realm of the basic structure - but we are equally entitled to claim that, in a social and historical scenario of deep inequality, fast industrialisation and mass urbanisation, a basic structure without a careful labour law is unjust. Trade unions and worker fights for labour rights had precisely such a target: bringing labour relationships into the basic structure, and thereby create a system of legal and social guarantees where certain forms of 'agreements' could be recognised for what they were, namely exploitation, and consequently outlawed. Along a similar line, international 'agreements' which obviously benefit one of the parties at the expense of the other do not reveal the presence of a global basic structure, if we are to conceive of the basic structure in strict legally coercive terms - but they might reveal an injustice precisely in the absence of effective mechanisms to declare these agreements void and not binding, or in the absence of measures meant at changing the underlying structure of incentives and rewards which make such agreements attractive to powerful global actors in the first place. If the comparison between international institutions and 'associations of civil society' is appropriate, what has to be noticed is that, in the domestic case, associations are left free to operate because there is a basic structure that constrains them and, if required, makes the necessary corrections. The relevance to justice of 'associations' might be much more significant - and potentially worrying - in a situation of anarchy than it is within the boundaries of a just basic structure. The specific account of the basic structure that I have put forward in this paper allows the disentangling of two issues that are usually 
confused with each other: (1) the fact that an area of social phenomena is not regulated by the (legally coercive) basic structure, and (2) whether that very lack of regulation constitutes an injustice of the basic structure itself. Thus, even if we grant that the basic structure is to be conceived of in strict legally coercive terms, and that consequently no global basic structure might exist, there may still be room for claiming that, if certain empirical and social conditions holds, it is unjust not to have or create specific institutional protections. This need not end up in the construction of a full-blown global basic structure which substitutes, pre-empts or trumps domestic ones, but in a more nuanced and context-sensitive assessment of the specific problems that certain categories of global interaction might have.

Therefore, the understanding of the basic structure that I have proposed in this paper is not automatically committed to the rejection of the idea that the actual global scenario raises problems of justice. On the contrary, precisely in virtue of its conceptual nature, it allows for a high degree of flexibility: we might concede that there is no global basic structure, and still have the option to argue that, in certain circumstances, precisely this absence is a problem of justice. The presence of particular, and particularly problematic, kinds of interaction may ground the necessity to build a basic structure - or, more modestly, basic structural elements. Of course, the issue of which kinds of interactions - and which corresponding vulnerabilities - are actually problematic must be decided through a combination of conceptual and empirical considerations. The result of my argument is simply to reopen a debate. My understanding of the basic structure cannot automatically deliver a specific position in the global justice debate. But what it can deliver is a rejection of the easy way out that, since there is no globally coercive basic structure, there is no problem of global justice.

\section{2. 'There actually are global institutions that are legally coercive in the relevant sense, but they are so 'thin' that it would be inappropriate to define them as a global basic structure.'}

This second argument is somewhat different from the first, although it is inspired by similar normative considerations. What both arguments share is a commitment to the idea that only legally coercive institutions are to count as candidates for a global basic structure. They differ, however, in the empirical assessment of the current global order. Whereas the first argument denies the presence of any properly coercive institutions at the global level, the second concedes that some such institutions exist - presumably, international public law, international property rights, intellectual property law, etc. Nevertheless, both arguments share the conclusion that no basic structure can be said to exist at the global level.

The issue at stake here is whether the thinness of the institutional background matters, and, if it does, to what extent. Given my specific understanding of basic structure, what really matters is what is meant by 'thinness'. If what is meant is something similar to what I have described under model X, then the idea underlying the argument must be the following: since the existing global 
institutions directly express commands or prohibitions only in a very limited area of phenomena, and leave most kinds of interaction unregulated, we cannot properly speak of a global basic structure. My reaction to this claim should by now be fairly predictable: I have already rejected model $\mathrm{X}$ as an inappropriate way of making sense of what the basic structure is. What should concern us is the overall structure of incentives and rewards that such a thin web of institutions engenders: if they do heavily influence the system they regulate by shaping the background of incentives and rewards for global actors in significantly different ways than other, equally 'thin', institutional settings would, then the claim that such a web is not a basic structure becomes problematic. Institutions that are 'thin' in abstracto - i.e. in what they directly prohibit or mandate in general, independently from the context in which they operate - may appear less 'thin' if we scrutinise them from a more holistic perspective; and I have argued that we do need to adopt such a holistic perspective, even at the domestic level. If the 'thinness' suggested by the argument is the one implied by model X, my reply is simply that this is not the right way to use the term 'thinness' with regard to institutions. Hence, my understanding of the basic structure allows me to reject this version of the 'thinness' argument. My notion of basic structure cannot, however, reject an alternative version of the 'thinness' argument: namely, that global institutions are 'thin' in that their actual impact is very limited, and that domestic factors play a much deeper and more important explanatory role as far as the behaviour and interaction of global actors is concerned. My account of the basic structure alone is silent with respect to this argument, since it must be acknowledged that the assessment of the argument is partly empirical; but my account can ground the conclusion that such an empirical assessment is required, since the naive version of the 'thinness' argument does not make any significant contribution as to whether there actually is a global basic structure.

\section{3. 'There is, indeed, a global basic structure, but it is not unjust. The global order might have undesirable effects; this, however, is due to patterns of behaviour and interaction that happen 'outside' the global basic structure.'}

This argument is a rather standard version of what Cohen calls 'the basic structure objection': principles of justice apply to the basic structure, not to what happens outside it. The actual legally coercive rules of the global basic structure are not morally objectionable: customary international law, international property rights, the respect of self-determination are all appropriate and morally legitimate rules. 'Chosen behaviour' within these rules might produce some undesirable effects, but this does not entail that the coercive global basic structure is actually unjust.

By way of example, let us consider the system of resource and borrowing privileges that allows those who are in power in a specific country to sell natural resources or borrow money in the name of that country. Our global system internationally recognize those who are in power in a country as legitimately entitled to take advantage of such privileges, and then holds the country accountable for the consequences that follow from decisions and agreements that are made in the 
name of such entitlements (for instance, paying off debts). Pogge ${ }^{36}$ notes that such a system is actually an incentive for 'authoritarian predators' to take power by force, due to the reward constituted by resource and borrowing privileges for those who successfully accomplish a coup d'état. By recognizing the entitlement to resource and borrowing privileges of illegitimate rulers and dictators, the global order makes life for democracies in developing countries harder, rather than easier. Moreover, Pogge continues, such privileges 'make it possible for oppressive and unrepresentative rulers to entrench themselves with arms and soldiers they buy with money they borrow abroad or get from resource sales' ${ }^{37}$ Finally, in spite of the authoritarian and oppressive nature of such leaders, it is the country's population that is then held responsible of bearing the costs of the agreements, including paying off debts. Resource and borrowing privileges are, in Pogge's view, one of the clearest examples of the injustice of the current global order.

The argument considered here acknowledges the existence of a global basic structure, but raises a series of perplexities against the claim that resource and borrowing privileges make the global basic structure unjust. The international rules governing the international transfer of resources and money, so the argument runs, is regulated by just rules - specifically, the respect of (1) international property rights (a country is entitled to full property of its natural resources); (2) the duty of non-intervention in another country's domestic affairs (those who are in power in a country are recognized by other global actors as legitimate leaders); and finally (3) pacta sunt servanda (a country has to respect the treaties and the agreements that it makes). Such a framework, so the argument continues, might have undesirable effects when specific countries that engage in international transactions are governed by regimes that are morally objectionable, but this does not make the overarching system of rules unjust. The rules are just, or at least neutral; they simply might have undesirable effects.

My response to this argument should also be reasonably predictable: the claim that international rules are just or neutral is based on the understanding of rules and institutions that I have described under model X. As I have argued with respect to the domestic case, a 'just' rule can perfectly contribute to the 'injustice' of the basic structure as a whole, if its contribution makes the overall system fail to satisfy the standard of justice that ought to be realized. Thus, for instance, if the adequate standard of justice is fair equality of opportunity, the demand on institutions is that such standard be realized - if necessary, by giving women special rights and special privileges. Similarly, in the case of the global order, the 'neutrality' of the rules in terms of content - narrowly conceived - is not what matters most: the global basic structure is just if its system of rules, taken as a whole, manages to realize the appropriate standard of justice in the actual system that it organizes. The fact that resource and borrowing privileges can, in abstracto, be consistent with rules whose content is just or neutral does not make the global

36. Pogge (2002), pp. 22-3, 113-15.

37. 'Global Justice as Moral Issue. Interviewing Thomas Pogge', interview conducted by Alessandro Pinzani, Ethic@ 4/1(June 2005), 1-6 <http://www.cfh.ufsc.br/ethic@/int41.pdf>. 
basic structure just - in the very same way in which sex-neutral legislation may fall short of justice in a sexist society where women need special protection. What we need to look at is the overall structure of incentives and rewards that such a system of rules engenders.

4. 'Even if we were to accept that there is some kind of global basic structure, domestic factors would still play a role in determining how different countries fare. Thus, even if there is a global basic structure, the implementation of a global distributive scheme seems somewhat unfair.'

The target of this argument is to point out that, even if there is such a thing as a global basic structure, it is implausible to presume that its impact is so pervasive as to pre-empt the role and the effects of domestic structures. Thus, we can still presume that some countries will behave as ants and others as grasshoppers, and if this were to have an impact on their level of wealth, would it not be disrespectful, as Rawls suggests, to implement an on-going redistributive scheme that takes resources from the former and transfers them to the latter?

In my account of the basic structure, such an argument does not necessarily have a destructive impact. My account of the basic structure allows us to disentangle two issues that other accounts fail to distinguish: (1) the criterion of justice that ought to be realized, and (2) which conditions have to be in place for us to be able to say that the criterion actually is realized. A theory can be more or less demanding in terms of (1), depending on the content of its criterion of justice; but it can also be more or less demanding in terms of (2), depending on how high standards are for concluding that the criterion of justice is actually realized. Because it requires the criterion of justice to be carefully adjusted to specific contexts and specific empirical circumstances, Model $\mathrm{Y}$ is demanding in terms of (2) whether or not it is also demanding in terms of (1). At the domestic level, 'justice as fairness' interpreted in terms of $\mathrm{X}$ is rather demanding in terms of (1), since Rawls' two principles are highly egalitarian. But it is not demanding at all in terms of (2), since it is sufficient that the institutional structure be not directly committed to normative ideals which actively and directly violate the two principles. By contrast, and for reasons that should by now be obvious, 'justice as fairness' in the domestic sphere, interpreted according to model $Y$, will tend to be demanding both in terms of (1) and in terms of (2).

Drawing on this account, if we (a) conceive of the basic structure in terms of $\mathrm{Y}$, and (b) agree with the empirical assessment that domestic factors are also important in determining the level of wealth and domestic justice of different countries, then we have reasons to lower our standards in terms of (1), but no reason to be less demanding in terms of (2). To put this point in other terms: it is perfectly reasonable to think that our criterion of justice might be less demanding in the global than in the domestic case, but not that it be realized in a less stringent way. Thus, for example, we may reasonably deny that a global difference principle is the right criterion of justice at the global level, and endorse something less demanding like, say, non-exploitation. However, there are no reasons to believe that the conditions of realization of a less demanding criterion should itself be 
less demanding and stringent. Thus, if non-exploitation is the right criterion for global justice, it would nevertheless have to be realized in terms of model $Y$ - i.e. by making sure that global actors are protected from exploitation in the specific context in which they operate, and adequately protected against the specific risks of exploitation that our global scenario entails. If this is the case, the claim that a global difference principle is too much for the global order is not as threatening for those who believe that much work still has to be done at the global level, as it is for those who endorse model X. If we endorse model Y, we can concede that the standard of global justice might be weaker than the difference principle, and still deny that this is where the action really is: advocates of model $\mathrm{Y}$ are more likely to argue that, at the global level, the real challenge is to make sure that the appropriate criterion of justice, whatever that might be, be properly realized with an adequately careful institutional implementation.

\section{Conclusion}

This paper has argued that a focus on the basic structure need not be sociologically naïve or politically conservative. More precisely, I have argued that it is not politically conservative because it is not sociologically naïve. Since a focus on the basic structure can be sensitive to the pervasive role social norms have in shaping a society' structure, it does not commit its advocates to claim, say, that inequalities between the sexes are not a concern of social justice as long as our laws are gender-neutral. I have then concentrated on what implications such an argument may have for the literature on global justice. I have contended that, even in this field, a basic structure approach need not generate pro status quo biases: it is possible to hold that the basic structure is the locus of social justice and to claim that the current global order is unjust, if certain empirical conditions apply. Hence, although I have not offered a positive argument in favour of the view that the global order is indeed unjust, I have argued that the absence of a world state is by far not enough to appease our conscience.

MIRIAM RONZONI

St Peter's College

University of Oxford

miriam.ronzoni@st-peters.oxford.ac.uk

\section{the global justice network}

